\title{
Long-Term Temporal Trends of Polychlorinated Biphenyls and Their Controlling Sources in China
}

\author{
Shizhen Zhao, ${ }^{\dagger, \perp}$ Knut Breivik, ${ }^{\ddagger} \S$ Guorui Liu,, Minghui Zheng, ${ }^{\prime \prime}$ Kevin C. Jones, ${ }^{\dagger}$ \\ and Andrew J. Sweetman*, ${ }^{*}$
}

${ }^{\dagger}$ Lancaster Environment Centre, Lancaster University, Lancaster, LA14YQ United Kingdom

${ }^{\ddagger}$ Norwegian Institute for Air Research, Box 100, NO-2027 Kjeller, Norway

${ }^{\S}$ Department of Chemistry, University of Oslo, Box 1033, NO-0315 Oslo, Norway

"State Key Laboratory of Environmental Chemistry and Ecotoxicology, Research Centre for Eco-Environmental Sciences, Chinese Academy of Sciences, P.O. Box 2871, Beijing 100085, China

${ }^{\perp}$ State Key Laboratory of Organic Geochemistry, Guangzhou Institute of Geochemistry, Chinese Academy of Sciences, Guangzhou 510640, China

\section{Supporting Information}

ABSTRACT: Polychlorinated biphenyls (PCBs) are industrial organic contaminants identified as persistent, bioaccumulative, toxic (PBT), and subject to long-range transport (LRT) with global scale significance. This study focuses on a reconstruction and prediction for China of long-term emission trends of intentionally and unintentionally produced (UP) $\sum_{7} \mathrm{PCBs}$ (UP$\mathrm{PCBs}$, from the manufacture of steel, cement and sinter iron) and their re-emissions from secondary sources (e.g., soils and vegetation) using a dynamic fate model (BETR-Global). Contemporary emission estimates combined with predictions from the multimedia fate model suggest that primary sources still dominate, although unintentional sources are predicted to become a main contributor from 2035 for PCB-28. Imported e-waste is predicted to play an increasing role until 2020-2030 on a national scale due to the decline of intentionally produced (IP) emissions. Hypothetical emission scenarios suggest that China could become a potential source to neighboring regions with a net output of $\sim 0.4 \mathrm{t} \mathrm{year}^{-1}$ by around 2050 . However, future emission scenarios and hence model results will be dictated by the efficiency of control measures.

\section{INTRODUCTION}

Polychlorinated biphenyls (PCBs) are industrial organic contaminants identified as persistent, bioaccumulative, toxic, and subject to long-range transport (LRT) with global scale significance. They are among the 12 persistent organic pollutants (POPs) initially regulated by the Stockholm Convention $^{1}$ to protect environmental and human health from these hazardous compounds. The cumulative global production of PCB was approximately 1300000 tons with only ca. 10000 tons produced in China since $1965 .^{2}$ These chemicals were mainly emitted as a direct result of intentional historical production, use, and disposal of products or accidental release. ${ }^{3}$ Though they have been banned for several decades, they are still of great concern because of the legacy of past usage, their persistence in the environment, their bioaccumulation in biota, and their potential toxicity. 4,5

PCBs can be emitted from both primary and secondary sources. Primary sources account for the main direct releases of PCBs to the environment from their major use categories, and secondary sources represent the re-emission from environ-

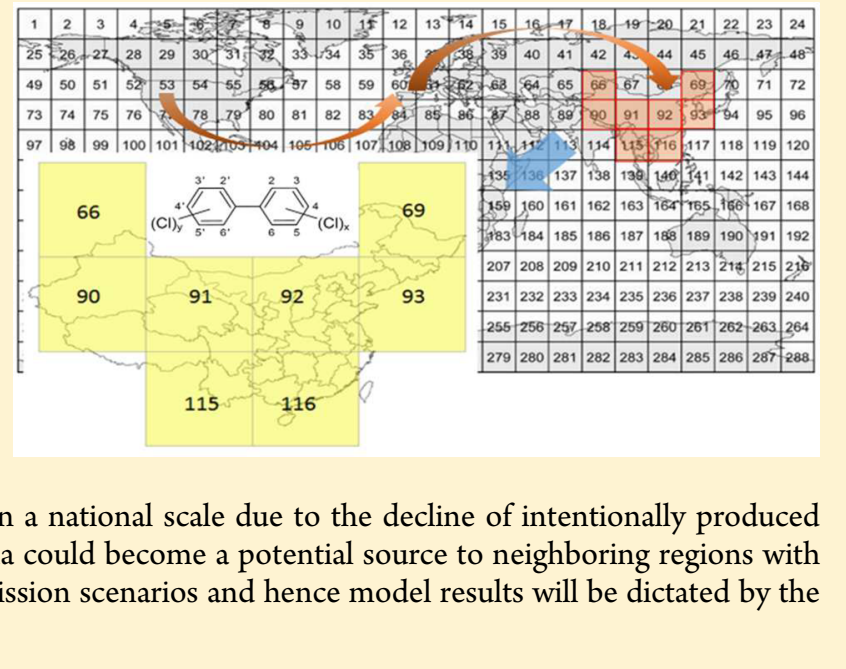

mental reservoirs including soils, sediments, and other contaminated compartments. Secondary sources can be viewed as "capacitors" that were charged with pollutants deposited from the atmosphere when emissions were higher and may now be net sources to the atmosphere. ${ }^{5}$ In industrialized countries, primary emissions of PCBs to the environment peaked in the early 1970s and largely occurred through leakage and losses from the PCB-containing products and systems. More recently, secondary sources have been demonstrated to represent a significant fraction among the total source inventory, especially in some remote areas. ${ }^{5}$ Under such conditions, the reduction in primary emissions may not be directly apparent in declining atmospheric concentrations due to ongoing releases from secondary sources. Therefore, an understanding of both

Received: October 21, 2016

Revised: January 26, 2017

Accepted: January 27, 2017

Published: January 27, 2017 
primary and secondary emissions is a prerequisite to successful control measures.

The production volume of PCBs in China accounts for approximately $1 \%$ of the global production. ${ }^{6}$ However, China has received $\mathrm{PCBs}$ from long-range atmospheric transport (LRAT) and trans-boundary movement of e-waste products containing PCBs. ${ }^{7}$ Therefore, the release of PCBs into the environment could be a combination of both primary and secondary emissions. Several studies suggested that contaminated soil could be a secondary source, particularly contributing to low-molecular-weight PCBs. ${ }^{8,9}$ Seasonal patterns of air-soil exchange have been observed when net volatilization occurred in summer. ${ }^{9-11}$ Therefore, the relative significance of primary and secondary emission is still under debate.

Primary PCB emissions into the atmosphere can be from intentionally produced (IP-PCB) and unintentionally produced PCBs (UP-PCBs) formed during industrial thermal processes. ${ }^{12,13}$ Emissions trends of IP-PCBs have been predicted by Breivik and his co-workers on a global scale and show a constantly decreasing trend since the middle of the 1970s, when production was phased out. ${ }^{2,3,14}$ This emission inventory was recently updated to cover the e-waste contributed IPPCBs. ${ }^{15}$ However, since the ban on manufacture and use of commercial products containing PCBs, UP-PCBs are likely to have become more important. ${ }^{16}$ Hogarh et al. (2012) reported that ambient air concentrations in China have increased by 1 order of magnitude over the period from 2004 to $2008 .{ }^{17}$ This is mainly linked to widespread industrial thermal process (e.g., iron ore processing and steel and cement production). ${ }^{16,17}$ As the economy in China grows, there is an increasing demand for construction materials such as steel and cement. China has contributed around $45 \%$ of global steel production and become the world's largest consumer of iron ore since $1993 .^{18}$ Consequently, the temporal trends and historical and future contribution of UP-PCBs need to be explored further. To understand which factors are controlling PCB burdens in environmental compartments in China, it is important to quantify the relative significance of primary emissions (controllable) versus secondary emissions (uncontrollable). An overestimate of the primary emissions may lead to costly and inefficient control measures, whereas an underestimation of the secondary emissions will result in an over-optimistic assessment of recovery rates following primary emission reductions. ${ }^{19} \mathrm{~A}$ further important question would be what are the most important primary sources, "intentional" or "unintentional", and do these overlap? These questions are of key interest for policy makers because it will affect their perception of the need to reduce or eliminate primary emissions and the effectiveness of emission reduction strategies.

The main aims of this study were (1) to simulate the individual contribution of primary sources (from imported ewaste and IP- and UP-PCBs emission) and secondary sources, (2) to evaluate modeling results in air and soil with limited observations in China, and (3) to provide suggestions to policy makers on rational control measures for PCBs. These objectives were achieved by using the BETR-Global fugacity-based model, ${ }^{20}$ a dynamic level IV fate and transport model, which has been evaluated and applied successfully for a range of organic contaminants, including PCBs. ${ }^{20-23}$

\section{MATERIALS AND METHODS}

2.1. Emission Data and Selected PCBs. In this study, the emission, fate and transport, covering both intentionally and unintentionally produced PCBs, were modeled under several scenarios for seven indicator $\sum_{7}$ PCBs (PCB-28, 52, 101, 118, 138,153 , and 180). These congeners were selected due to their representative physicochemical properties and contribution in technical mixtures of PCBs. ${ }^{24}$ The distribution of e-waste emission was accounted based on the location of e-waste facilities in China. ${ }^{15}$ Other assembled emission data were distributed into a $1^{\circ} \times 1^{\circ}$ latitude and longitude grid system using global population density as a surrogate. ${ }^{25}$ The physicochemical properties of selected congeners are presented in Table $S 1 .^{26,27}$

2.1.1. IP-PCBs Emission in China. The recently revised global emission inventory by Breivik and co-workers was utilized in this study ${ }^{15}$ using a dynamic mass balance and flow analysis to calculate 22 IP-PCBs from 1930 to $2100 .^{2,3,14}$ This emission inventory was recently developed to additionally account for the transport of e-waste. ${ }^{3,15}$ Scenarios of baseline IP and worst-case IP with or without considering imported ewaste as detailed elsewhere. ${ }^{15}$ They are used to explore the relative contribution of $\mathrm{PCB}$ from imported e-waste to China.

2.1.2. UP-PCBs Emission in China. Three major UP-PCB types were identified as representing dominant contributions to UP sources, which capture more than $90 \%$ of known UPsources so far. ${ }^{12,13}$ These were cement kilns, electric arc furnaces (EAF) used in steel making and the sintering process, that were also used in steel production. ${ }^{16}$ There is a potential underestimation of UP-PCB emissions because there are other UP-PCB sources (e.g., coking, secondary aluminum production, and thermal power stations) that have not been considered. ${ }^{13}$ Consequently, two scenarios were used to explore this potential uncertainty: (1) a default scenario using measured emission factors ${ }^{28}$ and (2) a "high" scenario using the measured emission factors multiplied by a factor of 10 as a conservative assumption because emission inventories may often be uncertain by at least an order of magnitude. ${ }^{29}$ These emission factors were assumed to be constant over time during each simulation.

A total of three source types (IP-PCB, UP-PCB, and secondary sources) were considered for past and future emission scenarios. The secondary sources were calculated using the BETR-Global model as described in detail in section 2.3. The recorded production volume (http://www.stats.gov. $\mathrm{cn} / \mathrm{tjsj} / \mathrm{ndsj} /$, accessed on 27/09/2015) and estimated production volume of cement, EAF-produced steel, and sinter iron ore between 1949 and 2100 are illustrated in Figure S1. The estimated annual emission data was assigned onto a $1^{\circ} \times$ $1^{\circ}$ grid map using population density as a surrogate. ${ }^{25}$ These estimates just represent a first approximation, which may not be appropriate for some large plants located near sources of raw materials and, thus, would not correlate with population density.

2.2. Selected Fate Model and Study Region. The BETR-Global model was used to predict the fate and distribution of PCBs with a spatial resolution of $15^{\circ}$ latitude $\times 15^{\circ}$ longitude and 288 grid cells. It was selected due to its relative coarse resolution. Because population density was used as a surrogate to the UP-PCB emission with high uncertainty. The coarse resolution of BETR-Global could potentially "even out" this simplification. Each grid cell consists of seven bulk compartments, which are ocean water, freshwater, planetary boundary layer (PBL), free atmosphere, soil, freshwater sediments, and vegetation. ${ }^{20}$ The model accounts for advective transport between the regions by air and water and 
intercompartment transport processes such as dry and wet deposition and reversible partitioning. ${ }^{21}$

The model simulations were performed at a global scale during the period 1930-2100 using a dynamic level IV structure that assumes nonsteady-state conditions. The study region focused on China as shown in Figure S2. The temperature in the upper and lower atmosphere is taken from the NCEP/NCAR reanalysis of climate data (https:// www.esrl.noaa.gov/psd/data/reanalysis/reanalysis.shtml). They are $15^{\circ} \times 15^{\circ}$ averages for the years 1960-1999. Multiyear model simulations repeat the same cycle of environmental conditions. Only emission to the lower air compartment was considered. The initial model concentration in all compartments was assumed to be zero.

2.3. Estimation of Source-Receptor Relationships. Multiple emission inventory scenarios were investigated to explore different source-receptor relationships. The employed emission profiles were defined as (1) baseline IP, with no imported e-waste and 5\% of the disposed e-waste subject to open burning; (2) worst-case IP scenario, considering imported e-waste and the fraction of open burning is $20 \%$. The scenarios of baseline IP and worst-case IP were defined in detail elsewhere. ${ }^{15}$ They are used to explore the relative contribution from imported e-waste to China; (3) default (IP + UP), with UP-PCBs and worst-case IP-PCBs sources combined and calculated UP-PCBs using measured emission factors; ${ }^{16}$ and (4) worst-case (IP + UP), combined worst-case IP-PCBs and "high" UP-PCBs using a factor of 10 as defined in section 2.1.2 to explore the uncertainty of emission factors for seven UPPCBs.

First of all, to examine individual contribution from imported e-waste and UP-PCBs, the emission scenarios of baseline IP, worst-case IP, and default (IP + UP) were investigated by allowing contaminants from both primary and secondary emissions in environmental reservoirs. Second, to distinguish primary and secondary sources, the default (IP + UP) scenario was repeated with re-emission from the "blocked" surface compartments. The "blocked processes" from surface-to-air included diffusion from soil, water, and vegetation to air as well as resuspension from soils via dust and from oceans via marine aerosol production. ${ }^{30}$ Third, to explore the role of China in its global context (sink or source), the model was also run using only the emission estimated within China (regional emission), while the emission to other parts of the world was disabled (extra-regional emission). The Chinese emission part was extracted from the global emission inventory according to eight selected grids.

\section{RESULTS AND DISCUSSION}

3.1. Evaluation with Measurements. First, the modeling results were evaluated using available measurement data to build confidence for further model exploration. A model such as the one presented here can only be evaluated to a limited extent, especially for a region where measurement data is scarce. However, it is also useful to assess the accuracy of model predictions when possible. The output from the model with the default scenario (IP + UP), over a limited period, was compared with available measured PCB data in air and soil. Because the BETR-Global model does not provide information on urban-rural gradients, model predictions were compared against observed background concentrations. Atmospheric PCBs concentrations have been measured in China over the past decade in rural and urban sites. ${ }^{31,32}$ Surveys providing
PCBs concentration data in background soils have been conducted in 2005 and $2013^{33,34}$ and normalized by total organic carbon (TOC). For comparisons to be made with studies that do not distinguish between PCB congeners 28 and 31 , PCB-28 was assumed to account for $55 \% .{ }^{27}$ This is a reflection of the composition of the technical mixtures.

Figures S11-S13 compare predicted and observed time trends in air and soil for PCB congeners. This comparison suggests that the model generally captures the main trends in observations over the period 2001 to 2008. The agreement between predicted and observed air concentrations is better for heavier PCBs than for the lighter congeners (PCB-28/52). Most modeled concentrations are within a factor of 3 compared to the limited observations in background air. The model tended to underestimate the atmospheric concentrations for PCB-28 and PCB-52, with the largest difference occurring in 2001 by a factor of 7 for PCB-52. This could be due to underestimated emission from local sources. ${ }^{35}$ The peak concentration, which occurred around 1970 predicted by the model, is difficult to confirm with measurements. However, several preliminary findings from dated sediment cores could potentially support the model estimation. The historical trend was observed to increase until the mid-1970s in a dated sediment core from the Yangtze River Estuary adjacent to the East Sea region and Pearl River Delta. ${ }^{36,37}$ Predicted concentrations increase again from the 1980s, mainly associated with imported electrical equipment containing PCBs and ewaste recycling activities in nearby regions. ${ }^{36,37}$

Soil responds at a much slower rate to changes in emissions than air, especially for the heavier and more-persistent PCB congeners. Measured surface soil concentrations from $2005^{33}$ and 2013 in forest soil ${ }^{34}$ were compared with model predictions and agreed well, within a factor of 4 except for tri-PCB congeners, although the measured concentrations varied over a wide range. Soil data showed similar results to the largest deviation observed for PCB-28 for both studies, indicating the greater underestimation of soil concentrations by over a factor of 100 . This may be caused by the combined effect of parameter uncertainty (e.g., soil depth and organic content), unaccounted emissions, or both. The measured data was limited to two sampling years, 2005 and 2013, but it showed evidence of a decrease for PCB-28 and PCB-101. However, for PCB-138 and PCB-153, an increase was observed from 0.28 to $0.42 \mathrm{ng} / \mathrm{g}$ OC $(\mathrm{dw})$ for PCB-138 and from 0.09 to $0.31 \mathrm{ng} / \mathrm{g}$ OC $(\mathrm{dw})$ for PCB-153. These differences are small but could be attributed to the more recalcitrant nature of heavier PCB congeners. $^{38}$

The homologue profile of PCBs (Figure S10) during the simulation period is also compared with observations. The predicted change in homologue trend is generally consistent with the measured profile. ${ }^{38}$ Many studies have been conducted around heavily polluted areas (i.e., "hotspots"), and much fewer data are available in background regions. Therefore, the high spatial variability of PCB concentrations in soil with relatively low numbers of measurements at the background sites makes it difficult to draw a reliable conclusion. A much larger data set would be required to establish reliable ranges for background concentrations to determine the whole picture of POPs pollution in China.

3.2. Temporal Trends of UP-PCBs in China. The predicted time trends for past and future emissions of 7PCBs as well as their individual contribution from imported e-waste and unintentional sources are illustrated in Figure 1. Profiles for 


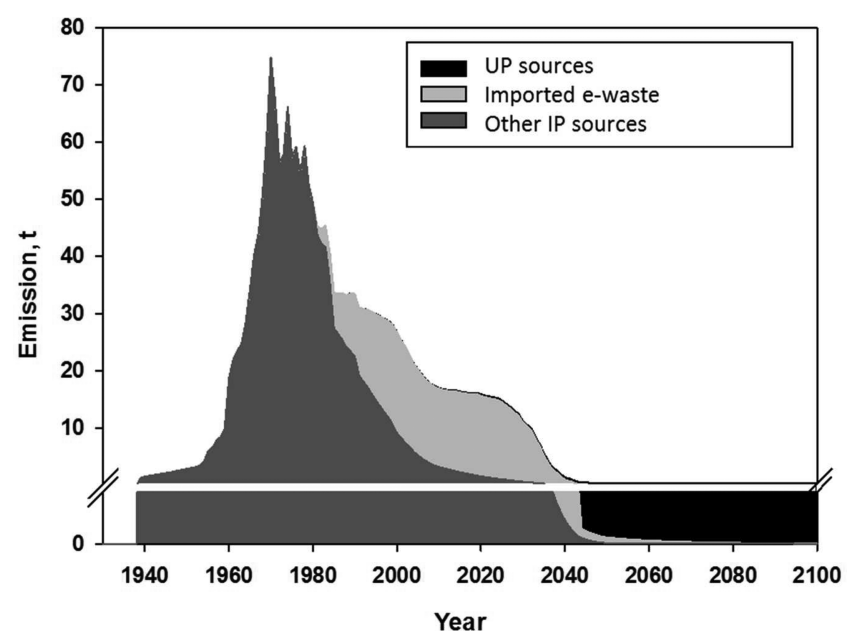

Figure 1. Predicted trends of total PCBs emission in China from 1930 to 2100 under the default scenario (IP + UP). The black area indicated the emission from UP sources; the light gray area indicated the emission from imported e-waste, and the dark gray area presented emission from other IP sources.

other congeners are presented in Figure S3. Because the optimum scenario of unintentional-sources is difficult to confirm with measurements, the default scenario (IP + UP) based on measured emission factors was assumed to be the most representative of reality and used for further discussion. In addition, the impact of an uncertainty factor of 10 on UP emissions from $\sum_{7}$ PCBs was also explored (see Figure S3).

The cumulative emission of intentionally produced $\sum_{7} \mathrm{PCBs}$ from 1930 to 2040 was extracted from ref 16 and estimated at 2300 tons in China (illustrated in Figure 1), with future emissions estimated to be about 2 tons from 2040 to 2100 . Emissions of $\sum_{7}$ UP-PCBs were predicted to be 9.5 tons between 1949 and 2040. However, their future emissions (2040-2100) were estimated around 23 tons under the default scenario with measured emission factors. Therefore, $\sum_{7} \mathrm{UP}$ PCB emissions only account for a minor portion of the total PCB emission, approximately $0.4 \%$ during the period of $1930-$ 2040. However, they are predicted to play an increasingly important role in the near future (2040-2100), accounting for up to $91 \%$ of the $\sum_{7}$ PCB (UP + IP) emissions.

The predicted atmospheric concentrations were almost identical for the three emission scenarios, over the period 1930 to 2010 for $\sum_{7}$ PCBs (see Figure S4). This further supports the assumption that UP-PCBs did not contribute significantly over that period. After 2010, however, predicted air concentrations started to diverge for each congener, attributed to different congener abundances among the UP-PCB sources. In addition, the identification of markers could be informative for future monitoring activities. Previously, PCB-118 was demonstrated to be a good marker congener to describe and evaluate the emission trends from the industrial thermal process because it falls in both classes of dioxin-like PCBs (dl-PCBs) and indicator PCBs. ${ }^{16}$ However, PCB-28 was also demonstrated to have a significant correlation with seven congeners. ${ }^{12}$ In this study, both relationships were explored for PCB-28 and PCB-118, and a correlation coefficient $\left(R^{2}\right)$ of 0.98 and 0.90 was observed $(p<0.001)$, respectively. Therefore, PCB-28 is suggested to be a useful indicator congener for atmospheric $\mathrm{PCBs}$ concentrations from three the considered emission sources.
For UP sources, PCB-28 was the dominant congener of the $\sum_{7} \mathrm{PCBs}$ emission, accounting for approximately $78 \%$ during $1930-2100$. It also contributes about $28 \%$ of the $\sum_{7} \mathrm{PCBs}$ (IP + UP) emissions over the period dominated by IP-PCBs (1940-2010). The historical predominance of IP-PCB-28 was anticipated as tri-PCBs were dominant in commercial mixtures used in China. ${ }^{24}$ Predicted atmospheric concentrations of PCB28 show the largest difference under three scenarios as defined in section 2.3, which is up to 6 orders of magnitude (Figure S4). This difference is minimal for PCB-153 in Figure S4, which suggests that UP sources are more important for lighter PCBs (PCB-28/52) than heavier ones (PCB-138/153), contributing less than $50 \%$ to concentrations in air. In addition, atmospheric concentrations of different congeners will be dominated by unintentional sources at different times. For example, as presented in Figure S4, PCB-28 is predicted to be dominated by UP-PCB sources from 2035 due to high abundance in emission sources, while PCB-52 will be dominated by UP sources after 2040 with a relatively gradual shift.

3.3. Contribution from Imported E-Waste. The transboundary movements of e-waste from developed countries to developing countries has made it a potentially substantial inventory and emission source of PCBs., ${ }^{75}$ Therefore, the contribution of imported e-waste was explored to identify its influence (national or regional in China). The cumulative emissions from imported e-waste are predicted to contribute around $30 \%$ to the total emissions for seven congeners during 1930-2100. PCB-180 received the highest percentage (45\%) from imported e-waste. In terms of the cumulative atmospheric concentration in different study grids (see Figure S6), the contribution of e-waste was largest for Grid 116 (which included most e-waste recycling sites in South China), making up more than $30 \%$ of all congeners.

The influence of e-waste varied in different sampling years as illustrated in Figure S5. The import of e-waste into China started around 1980. It is obvious that the Grid 116 received the highest burden in atmosphere supplied by imported e-waste because the main e-waste recycling sites (e.g., Guiyu and Qingyuan) with informal recycling activities are located here. ${ }^{39}$ Evident regional differences are predicted in terms of influence from imported-waste, e.g., grid cell 66 (mainly covering Xinjiang) received the least e-waste associated PCBs, as it is remote from the e-waste recycling sites. Imported e-waste is predicted to play an increasing role until 2020-2030 on a national scale in relative terms, when grid cell 116 received more than $90 \%$ of input contributed by imported e-waste. This is not because PCBs produced by imported e-waste will increase in the period but rather because other IP sources are on a continuous decline since the ban on production. After 2030, the relative contribution from imported e-waste is predicted to diminish (Figure S5), representing less than 5\% to the total modeled air concentration by 2100 . However, the future emissions of e-waste may be different to the emission scenario used herein, largely depending on Chinese and international control strategies. For instance, Chinese government had issued a variety of laws and legislation to establish a formal e-waste recycling system. ${ }^{40}$ If the e-waste treatment gradually transits from open-burning by backyard workshop to integrated recycling process by qualified companies, the PCBs emission may decline faster than anticipated.

3.4. Contribution from Secondary Sources. Being able to distinguish between primary and secondary sources is important for understanding our ability to control sources and 
to aid policy makers to develop the most effective control measures. The advection into (and out of) China from the wider Asian region also needs to be quantified to place China's activities into a regional context. Therefore, the primary and secondary sources from China (region) and out of China (extra-region) were estimated for PCB-28 and PCB-153 (see Figure S7a,b). In addition, the individual contribution of secondary sources from soil, water, and vegetation to air was explored (Figure S7c,d), where regional primary and secondary emissions represent emissions from the domestic sources (China), while extra-regional and primary emissions represent the emissions from outside China as a result of LRAT.

When secondary sources were separated into regional and extra-regional, the profiles for PCB-28 and PCB-153 were similar until 2030 (see Figure S7). The extra-regional primary and secondary sources dominate the emission during the initial period from 1930 to 1960 for both PCB-28 and PCB-153. During that period, China did not have any domestic production or usage of PCBs. Therefore, LRAT would have been responsible for supplying $\mathrm{PCB}$ to the Chinese environment. However, when China started to produce PCBs in 1964, primary sources became increasingly important and had provided a steady contribution of approximately $70 \%$, which is predicted to continue until around 2030. Afterward, both congeners are predicted to behave differently. Future levels for PCB-28 are predicted to be mainly dominated by regional primary emission, and PCB-153 is mostly controlled by extraregional secondary sources. This could be due to PCB-28 mainly being supplied by ongoing and increasingly important UP sources, as discussed in section 3.2. In contrast, primary sources of PCB-153 should gradually decline within China, with secondary extra-regional emission becoming slowly more important.

Several studies have suggested that the main contributor to PCB emission should move from primary to secondary sources as production and use of PCBs declines. ${ }^{1,41}$ In China, the same trend can be seen for PCB-28 when simulations were performed only considering IP-PCBs (see Figure S8b). However, when taking UP-PCB into account, it appears that the primary sources remained dominant over the whole simulation period as in Figure S8a. As for the individual sources of UP-PCBs, the main contribution to emissions moved from cement kilns to EAF production over the period 2010 to 2020 (see Figure S9). EAF allows steel to be made from $100 \%$ scrap, and as a result, it could greatly reduce energy consumption. ${ }^{42}$ Thus, this technology is being strongly promoted. However, without effective control measures, EAF may have potential to cause increased emission of UP-PCBs.

3.4.1. Re-emission from Soil to Air. The exchange of POPs across the air-soil interface is one of the most important processes determining their long-term environmental fate, as the soil is thought to be a major reservoir in the terrestrial environment. ${ }^{11}$ When individual contribution of secondary sources from soil and vegetation for PCB-153 was explored (see Figure S7c,d), vegetation was predicted to dominate until 2030, with soil gradually becoming the main secondary source. This is a reflection of difference in the relative size of vegetation and soils as storage compartments. Delayed re-emissions normally occur from compartments that are slow to respond to changes in atmospheric concentrations, such as soils and the oceans. $^{30}$ Therefore, soil represents an initial sink for PCBs until it reaches equilibrium with air, after which it becomes a net source as primary emissions decline. ${ }^{8}$ It is important to take into account that these calculations assume a well-mixed soil depth of $20 \mathrm{~cm}$, and increasing the depth would increase soil capacity ${ }^{43}$ and vice versa.

Secondary emissions also occur from vegetation, although over a much shorter time-scale as vegetation responds rapidly to the changes in atmospheric concentrations. ${ }^{30}$ The model suggests that vegetation is a dominant secondary source for the whole simulation period for PCB-28 (see Figure S7c). This may be because primary sources are controlling the emission to the atmosphere, with soils acting as a reservoir during the simulated period. It was demonstrated that atmospheric deposition is the main contamination pathway for vegetation rather than uptake from the soil, determined based on a study of paddy rice in China. ${ }^{44}$

3.4.2. Analysis of Compartment Response Times. The roles of soil and vegetation compartments as secondary sources can be further explained by model calculations. Taking air (A), soil $(\mathrm{S})$ and vegetation $(\mathrm{V})$ as examples, the "storage capacity" of each medium can be calculated using compartment volume $(V$, $\left.\mathrm{m}^{3}\right)$ and fugacity capacity $\left(Z, \mathrm{~mol} \mathrm{~m}^{-3} \mathrm{~Pa}^{-1}\right)$. For PCB-28, the $V_{\mathrm{S}} Z_{\mathrm{S}}$ is $2.6 \times 10^{15} \mathrm{~mol} \mathrm{~Pa}^{-1}, V_{\mathrm{v}} Z_{\mathrm{v}}$ is $2.5 \times 10^{12}$, and $V_{\mathrm{A}} Z_{\mathrm{A}}$ is 7.4 $\times 10^{11} \mathrm{~mol} \mathrm{~Pa}^{-1}$. Thus, the soil has approximately 3500 times the storage capacity of the air and has approximately 1000 times the capacity of the vegetation. The transport parameter $D$ value for soil-to-air transfer $D_{\mathrm{SA}}$ is $2.3 \times 10^{9} \mathrm{~mol} \mathrm{~Pa}^{-1} \mathrm{~h}^{-1}$, and vegetation-to-air transfer, $D_{\mathrm{VA}}$ is $9.6 \times 10^{9} \mathrm{~mol} \mathrm{~Pa}^{-1} \mathrm{~h}^{-1}$. The characteristic time $(V Z / D)$ is the average time that a chemical "spends" in a single compartment and is the first indication of persistence. $^{45}$ This was calculated to be approximately 92 years and 10 days in soil and vegetation, respectively. ${ }^{46}$ Therefore, PCB-28 in the atmosphere will rapidly exchange with the vegetation as it attempts to approach equilibrium. In addition, the pathways of air-to-soil and vegetation-to-soil were also calculated to compare the relative importance of these two pathways. The calculations suggest that the characteristic time from air to soil is 18 days, and that for vegetation to soil is about one year. However, leaves can represent a large effective surface area that is greater than the soil surface area covered by the vegetation ${ }^{47}$ and so may represent an important deposition pathway for PCBs.

3.5. Atmospheric Advection. The importance of atmospheric advection between Chinese study regions and the extra-region was investigated and the results presented in Figure 2 for two contrasting years 1980 and 2050, respectively representing the "in-use" and "phase-out" periods. PCB production and use were restricted around $1974,{ }^{2}$ and peak emissions were expected around 1980. At that time, the central part of China (grids 91 and 92) acted as a PCB storage

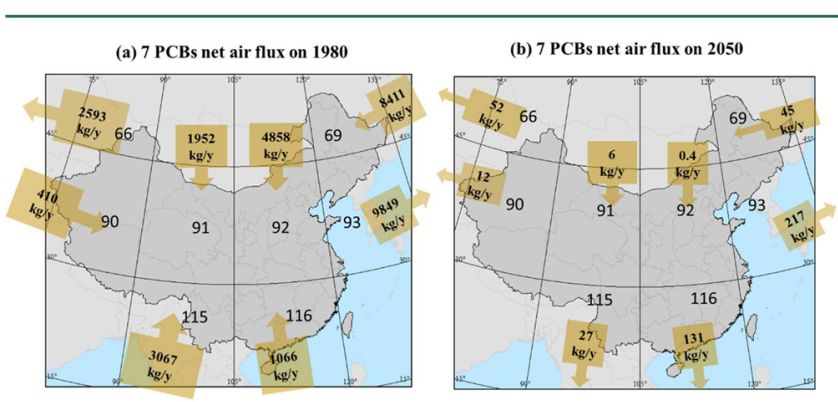

Figure 2. Net flux of seven indicator PCBs atmospheric advection between region and extra-region on 1980 (a) and 2050 (b), using the worst-case emission scenario (IP + UP). 
reservoir, while east of the country, as industrialized areas, acted as sources of PCBs to outside regions. It is interesting to note that the western parts of the country, which are not highly industrialized, have been acting as a net source, which may be attributed to high abundance of lighter PCB congeners in China. Their volatility and advection from the rest of the world or low TOC in these soils may be responsible. When looking at future predictions up to 2050, the central part of China is still predicted to receive $\mathrm{PCBs}$ from industrialized regions with decreasing quantity. The direction of the net flux changes from west and southern parts. When China as a whole is examined, the model predicts that this country has moved from a sink with a net atmospheric input of $\sim 7 \mathrm{t}^{\text {year }}{ }^{-1}$ for seven indicator PCBs to acting as a potential source to neighboring regions with a net output of $\sim 0.4 \mathrm{t}_{\text {year }}{ }^{-1}$. However, model results will be dictated by the efficiency of relative control measures.

3.6. Uncertainty. The emission inventory and environmental concentrations estimated in this study contain high levels of uncertainty caused by a wide range of factors. One of the most important uncertainties is the comprehensive identification of e-waste sources. Although the domestic generation of e-waste and its import from overseas have generally been captured in the current inventory, several types of electronic equipment were not considered (e.g., large household appliances and telecommunication equipment), which are still increasing. These may be considered in future work, although PCB production has been banned. ${ }^{7}$ Another concern is the difficulty in tracking illicit import of e-waste without effective regulation in China. A complementary approach to tracking the sources, flows, and destination of ewaste could provide further insights into the emission of ewaste pollutants. ${ }^{7}$

For the emission of UP-PCBs, only three major industrial processes were considered in this study. Other industrial sources could also contribute to the emission of UP-PCBs, such as secondary zinc smelting and thermal-wire reclamation. ${ }^{16}$ However, the individual congener profile of many industrial processes is lacking, and using emission factors from other countries has been shown to be misleading. ${ }^{12}$ For example, when comparing the emission factors used in this study ${ }^{16}$ with those reported from other countries, large differences were observed. Emission factors for cement production were up to 1000 times lower here than those used in the Japanese Toolkit. ${ }^{13}$ This could be due to the fact that the use of industrial thermal process, such as waste incinerators fed on alternative waste material, is not very common in China. Even within this study, there were wide variations of observed emission factors in the same type of plants in China with up to 100 times difference in the most extreme case. ${ }^{16}$ Therefore, using emission factors from other countries should only be recommended when domestic measurements are not available. Even then, caution should be taken. These differences also highlight the need for a more systematic survey of emission sources on a national scale to provide an unbiased and comprehensive reference for the emission inventory. A better characterization of emission factors is essential to help to produce a more accurate estimation of the time trends in the future.

The actual sources of PCBs via industrial processes also needs to be further scrutinized. Because PCBs are formed by more than just de novo synthesis or precursors, they may also be present in the raw materials. ${ }^{48}$ For example, PCB concentrations in iron ores were reported to be around 1-
$1.6 \mathrm{mg} \mathrm{t}^{-1}$ in a European sinter plant. ${ }^{49}$ They are likely to be destroyed mostly in the combustion zone but may be driven off due to their volatility. Therefore, it is very important but also a great challenge to differentiate the portion existing in the raw material and from new formation, to avoid double accounting for emission estimation and minimize input of contaminants going into industrial thermal processes or end-of-pipe measures.

The Chinese cement industry uses coal almost exclusively as fuel. ${ }^{50}$ There is very little use of alternative fuels (defined as waste materials with heat value more than $4000 \mathrm{kcal} \mathrm{kg}^{-1}$ for cement clinker burning) or the compression of waste materials (defined as the incineration of wastes for disposal purposes) in cement production. However, Chinese laws and policies now tend to encourage industry to use alternative fuels and waste materials. ${ }^{50}$ This may result in more recycled waste material being used for cement production.

In the steel and iron industries, the raw materials are mainly from internally produced steel scrap with some imported from aboard. The process of scrap preheating used in EAF may result in higher emissions of PCBs from contaminated scrap with paints and lubricants containing PCBs, which could be minimized post-combustion using additional oxygen burners. ${ }^{49}$ However, the related information is very limited in China. For recycled scrap, it is forbidden to have hazardous material with more than $50 \mathrm{mg} \mathrm{kg}^{-1} \mathrm{PCBs}$, which is regulated by the Chinese government (GB13015-91). Thus, the impact caused by the presence of PCBs in raw materials for steel industry is assumed to be negligible.

In this study, population density was used to distribute PCBs emission to each grid cell. For the UP-PCBs, high uncertainty may exist due to the recent movement of industrial sources from urban to rural or semirural areas. For example, most PCBcontaining equipment is stored at special sites after they have become waste. However, due to poor management and storage conditions, PCBs from some of these special storage locations have leaked into the environment of surrounding areas, especially to the soil. ${ }^{32,38}$

3.7. Implications for Control Measures. The environmental response to regulatory measures for the control of persistent chemicals can be very slow and substance-specific. ${ }^{51}$ Further, regional differences are also anticipated, particularly for a large country with varied geographical variations and levels of economic development like China. For this reason, an effective strategy should be developed and implemented as early as possible. Results from this study suggest that the effectiveness of emission control measures may vary significantly for individual substances and specific regions. For example, primary sources are still predominant for PCB-28, which means controllable sources could be effectively mitigated via implementing policy and regulations, especially for controlling UP-PCBs from industrial processes. The predictions suggest that UP-PCBs had little impact on past emission profile but may potentially provide a greater contribution from around 2050 if current industrial thermal processes continue without further control strategies. Although the emission abatement techniques have been developed, further work is needed to control POPs from industrial activities and requires on-site monitoring. ${ }^{28}$ Nevertheless, this may not work well for PCB153 and PCB-180 because imported e-waste is a more important contributor at this stage, particularly in the southern part of China. 


\section{ASSOCIATED CONTENT}

\section{S Supporting Information}

The Supporting Information is available free of charge on the ACS Publications website at DOI: 10.1021/acs.est.6b05341.

Detailed information on chemical properties, PCB production history in China, prediction approach of UP-PCBs emission, and additional model results. (PDF)

\section{AUTHOR INFORMATION}

\section{Corresponding Author}

*Phone: +44 (0) 1524 594715; fax: +44 (0) 1524 594715; email: a.sweetman@lancaster.ac.uk.

ORCID ${ }^{\circ}$

Andrew J. Sweetman: 0000-0001-9230-8536

Notes

The authors declare no competing financial interest.

\section{ACKNOWLEDGMENTS}

K.B. was supported by the Research Council of Norway (grant no. 213577). Thanks go to Dr. Matthew MacLeod and Dr. Henry Wöhrnschimmel for their guidance on running the BETR-Global model. Thanks go to Dr. Stefan Pauliuk and Prof. Zeyi Jiang for offering data estimated production of EAF and iron sinter.

\section{REFERENCES}

(1) UNEP. The Stockholm Convention on Persistent Organic Pollutants; United Nations Environmental Programme: Nairobi, Kenya, 2001.

(2) Breivik, K.; Sweetman, A.; Pacyna, J. M.; Jones, K. C. Towards a global historical emission inventory for selected PCB congeners - a mass balance approach 1 . Global production and consumption. Sci. Total Environ. 2002, 290 (1-3), 181-198.

(3) Breivik, K.; Sweetman, A.; Pacyna, J. M.; Jones, K. C. Towards a global historical emission inventory for selected PCB congeners - a mass balance approach 2. Emissions. Sci. Total Environ. 2002, 290 (13), 199-224.

(4) Jones, K. C.; de Voogt, P. Persistent organic pollutants (POPs): state of the science. Environ. Pollut. 1999, 100 (1-3), 209-221.

(5) Nizzetto, L.; Macleod, M.; Borgå, K.; Cabrerizo, A.; Dachs, J.; Guardo, A. D.; Ghirardello, D.; Hansen, K. M.; Jarvis, A.; Lindroth, A.; Ludwig, B.; Monteith, D.; Perlinger, J. A.; Scheringer, M.; Schwendenmann, L.; Semple, K. T.; Wick, L. Y.; Zhang, G.; Jones, K. C. Past, Present, and Future Controls on Levels of Persistent Organic Pollutants in the Global Environment. Environ. Sci. Technol. 2010, 44 (17), 6526-6531.

(6) Liu, L. Y.; Ma, W. L.; Jia, H. L.; Zhang, Z. F.; Song, W. W.; Li, Y. F. Research on persistent organic pollutants in China on a national scale: 10 years after the enforcement of the Stockholm Convention. Environ. Pollut. 2016, 217, 70-81.

(7) Breivik, K.; Armitage, J. M.; Wania, F.; Jones, K. C. Tracking the global generation and exports of e-waste. Do existing estimates add up? Environ. Sci. Technol. 2014, 48 (15), 8735-43.

(8) Li, Y. F.; Harner, T.; Liu, L.; Zhang, Z.; Ren, N. Q.; Jia, H.; Ma, J.; Sverko, E. Polychlorinated biphenyls in global air and surface soil: distributions, air-soil exchange, and fractionation effect. Environ. Sci. Technol. 2010, 44 (8), 2784-90.

(9) Wang, X.-p.; Sheng, J.-j.; Gong, P.; Xue, Y.-g.; Yao, T.-d.; Jones, K. C. Persistent organic pollutants in the Tibetan surface soil: Spatial distribution, air-soil exchange and implications for global cycling. Environ. Pollut. 2012, 170, 145-151.

(10) Wang, Y.; Cheng, Z.; Li, J.; Luo, C.; Xu, Y.; Li, Q.; Liu, X.; Zhang, G. Polychlorinated naphthalenes (PCNs) in the surface soils of the Pearl River Delta, South China: Distribution, sources, and air-soil exchange. Environ. Pollut. 2012, 170, 1-7.
(11) Cousins, I. T.; Beck, A. J.; Jones, K. C. A review of the processes involved in the exchange of semi-volatile organic compounds (SVOC) across the air-soil interface. Sci. Total Environ. 1999, 228 (1), 5-24.

(12) Cui, S.; Fu, Q.; Ma, W.-L.; Song, W.-W.; Liu, L.-Y.; Li, Y.-F. A preliminary compilation and evaluation of a comprehensive emission inventory for polychlorinated biphenyls in China. Sci. Total Environ. 2015, 533 (0), 247-255.

(13) Cui, S.; Qi, H.; Liu, L. Y.; Song, W. W.; Ma, W. L.; Jia, H. L.; Ding, Y. S.; Li, Y. F. Emission of unintentionally produced polychlorinated biphenyls (UP-PCBs) in China: Has this become the major source of PCBs in Chinese air? Atmos. Environ. 2013, 67, 73-79.

(14) Breivik, K.; Sweetman, A.; Pacyna, J. M.; Jones, K. C. Towards a global historical emission inventory for selected PCB congeners - A mass balance approach: 3. An update. Sci. Total Environ. 2007, 377 (2-3), 296-307.

(15) Breivik, K.; Armitage, J. M.; Wania, F.; Sweetman, A. J.; Jones, K. C. Tracking the Global Distribution of Persistent Organic Pollutants Accounting for E-Waste Exports to Developing Regions. Environ. Sci. Technol. 2016, 50 (2), 798-805.

(16) Liu, G. R.; Zheng, M. H.; Cai, M. W.; Nie, Z. Q.; Zhang, B.; Liu, W. B.; Du, B.; Dong, S. J.; Hu, J. C.; Xiao, K. Atmospheric emission of polychlorinated biphenyls from multiple industrial thermal processes. Chemosphere 2013, 90 (9), 2453-2460.

(17) Hogarh, J. N.; Seike, N.; Kobara, Y.; Habib, A.; Nam, J.-J.; Lee, J.-S.; Li, Q.; Liu, X.; Li, J.; Zhang, G.; Masunaga, S. Passive air monitoring of PCBs and PCNs across East Asia: A comprehensive congener evaluation for source characterization. Chemosphere 2012, 86 (7), 718-726.

(18) Feng, L. China's steel industry: Its rapid expansion and influence on the international steel industry. Resour. Policy 1994, 20 (4), 219234.

(19) Breivik, K.; Alcock, R.; Li, Y. F.; Bailey, R. E.; Fiedler, H.; Pacyna, J. M. Primary sources of selected POPs: regional and global scale emission inventories. Environ. Pollut. 2004, 128 (1-2), 3-16.

(20) Macleod, M.; Riley, W. J.; Mckone, T. E. Assessing the influence of climate variability on atmospheric concentrations of polychlorinated biphenyls using a global-scale mass balance model (BETR-global). Environ. Sci. Technol. 2005, 39 (17), 6749-6756.

(21) Lamon, L.; Von Waldow, H.; Macleod, M.; Scheringer, M.; Marcomini, A.; Hungerbuhler, K. Modeling the global levels and distribution of polychlorinated biphenyls in air under a climate change scenario. Environ. Sci. Technol. 2009, 43 (15), 5818-24.

(22) MacLeod, M.; von Waldow, H.; Tay, P.; Armitage, J. M.; Wöhrnschimmel, H.; Riley, W. J.; McKone, T. E.; Hungerbuhler, K. BETR Global-A geographically-explicit global-scale multimedia contaminant fate model. Environ. Pollut. 2011, 159 (5), 1442-1445.

(23) MacLeod, M.; Woodfine, D. G.; Mackay, D.; McKone, T.; Bennett, D.; Maddalena, R. BETR North America: a regionally segmented multimedia contaminant fate model for North America. Environ. Sci. Pollut. Res. 2001, 8 (3), 156-163.

(24) Fu, J.; Mai, B.; Sheng, G.; Zhang, G.; Wang, X.; Peng, P. a.; Xiao, X.; Ran, R.; Cheng, F.; Peng, X.; Wang, Z.; Wa Tang, U. Persistent organic pollutants in environment of the Pearl River Delta, China: an overview. Chemosphere 2003, 52 (9), 1411-1422.

(25) Li, Y. F.; McMillan, A.; Scholtz, M. T. Global HCH usage with 1 degrees $\mathrm{xl}$ degrees longitude/latitude resolution. Environ. Sci. Technol. 1996, 30 (12), 3525-3533.

(26) Schenker, U.; MacLeod, M.; Scheringer, M.; Hungerbuhler, K. Improving data quality for environmental fate models: a least-squares adjustment procedure for harmonizing physicochemical properties of organic compounds. Environ. Sci. Technol. 2005, 39 (21), 8434-41.

(27) Breivik, K.; Czub, G.; McLachlan, M. S.; Wania, F. Towards an understanding of the link between environmental emissions and human body burdens of PCBs using CoZMoMAN. Environ. Int. 2010, 36 (1), 85-91.

(28) Liu, G.; Zheng, M.; Jiang, X.; Jin, R.; Zhao, Y.; Zhan, J. Insights into the emission reductions of multiple unintentional persistent 
organic pollutants from industrial activities. Chemosphere 2016, 144, $420-424$.

(29) Annema, J.; Beurskens, J.; Bodar, C. Evaluation of PCB Fluxes in the Environment; report no.601014011; National Institute for Public Health and the Environment (RIVM): Bilthoven, The Netherlands, 1995.

(30) Wohrnschimmel, H.; MacLeod, M.; Hungerbuhler, K. Global multimedia source-receptor relationships for persistent organic pollutants during use and after phase-out. Atmos. Pollut. Res. 2012, 3 (4), 392-398.

(31) Jaward, T. M.; Zhang, G.; Nam, J. J.; Sweetman, A. J.; Obbard, J. P.; Kobara, Y.; Jones, K. C. Passive air sampling of polychlorinated biphenyls, organochlorine compounds, and polybrominated diphenyl ethers across Asia. Environ. Sci. Technol. 2005, 39 (22), 8638-8645.

(32) Xing, X.; Lu, Y. L.; Dawson, R. W.; Shi, Y. J.; Zhang, H.; Wang, T. Y.; Liu, W. B.; Ren, H. C. A spatial temporal assessment of pollution from PCBs in China. Chemosphere 2005, 60 (6), 731-739.

(33) Ren, N.; Que, M.; Li, Y. F.; Liu, Y.; Wan, X.; Xu, D.; Sverko, E.; $\mathrm{Ma}$ J. Polychlorinated biphenyls in Chinese surface soils. Environ. Sci. Technol. 2007, 41 (11), 3871-6.

(34) Zheng, Q.; Nizzetto, L.; Mulder, M. D.; Sanka, O.; Lammel, G.; Li, J.; Bing, H.; Liu, X.; Jiang, Y.; Luo, C.; Zhang, G. Does an analysis of polychlorinated biphenyl (PCB) distribution in mountain soils across China reveal a latitudinal fractionation paradox? Environ. Pollut. 2014, 195, 115-122.

(35) Xing, Y.; Lu, Y. L.; Dawson, R. W.; Shi, Y. J.; Zhang, H.; Wang, T. Y.; Liu, W. B.; Ren, H. C. A spatial temporal assessment of pollution from PCBs in China. Chemosphere 2005, 60 (6), 731-739.

(36) Yang, H.; Zhuo, S.; Xue, B.; Zhang, C.; Liu, W. Distribution, historical trends and inventories of polychlorinated biphenyls in sediments from Yangtze River Estuary and adjacent East China Sea. Environ. Pollut. 2012, 169, 20-26.

(37) Mai, B. X.; Zeng, E. Y.; Luo, X. J.; Yang, Q. S.; Zhang, G.; Li, X. D.; Sheng, G. Y.; Fu, J. M. Abundances, depositional fluxes, and homologue patterns of polychlorinated biphenyls in dated sediment cores from the Pearl River Delta, China. Environ. Sci. Technol. 2005, 39 (1), 49-56.

(38) Zhang, Z.; Liu, L.; Li, Y.-F.; Wang, D.; Jia, H.; Harner, T.; Sverko, E.; Wan, X.; Xu, D.; Ren, N.; Ma, J.; Pozo, K. Analysis of Polychlorinated Biphenyls in Concurrently Sampled Chinese Air and Surface Soil. Environ. Sci. Technol. 2008, 42 (17), 6514-6518.

(39) Chen, S. J.; Tian, M.; Zheng, J.; Zhu, Z. C.; Luo, Y.; Luo, X. J.; Mai, B. X. Elevated levels of polychlorinated biphenyls in plants, air, and soils at an E-waste site in Southern China and enantioselective biotransformation of chiral PCBs in plants. Environ. Sci. Technol. 2014, 48 (7), 3847-55.

(40) Zhang, S.; Ding, Y.; Liu, B.; Pan, D. a.; Chang, C.-c.; Volinsky, A. A. Challenges in legislation, recycling system and technical system of waste electrical and electronic equipment in China. Waste Manage. 2015, 45, 361-373.

(41) Harner, T.; Mackay, D.; Jones, K. C. Model of the long-term Exchange of PCBs between soil and the atmosphere in the southern U.K. Environ. Sci. Technol. 1995, 29 (5), 1200-9.

(42) Pauliuk, S.; Milford, R. L.; Muller, D. B.; Allwood, J. M. The steel scrap age. Environ. Sci. Technol. 2013, 47 (7), 3448-3454.

(43) Sweetman, A. J.; Valle, M. D.; Prevedouros, K.; Jones, K. C. The role of soil organic carbon in the global cycling of persistent organic pollutants (POPs): interpreting and modelling field data. Chemosphere 2005, 60 (7), 959-972.

(44) Bi, X.; Chu, S.; Xu, X. Transport of PCB in contaminated paddy fields. Acta Scientiae Cirumstantiae 2001, 21 (4), 454-458.

(45) Mackay, D. Multimedia Environmental Models: The Fugacity Approach, 2nd Edition; Taylor \& Francis: Abingdon, United Kingdom, 2001.

(46) Sweetman, A. J.; Cousins, I. T.; Seth, R.; Jones, K. C.; Mackay, D. A dynamic level IV multimedia environmental model: Application to the fate of polychlorinated biphenyls in the United Kingdom over a 60-year period. Environ. Toxicol. Chem. 2002, 21 (5), 930-940.
(47) Moeckel, C.; Nizzetto, L.; Strandberg, B.; Lindroth, A.; Jones, K. C. Air-boreal forest transfer and processing of polychlorinated biphenyls. Environ. Sci. Technol. 2009, 43 (14), 5282-9.

(48) Roudier, S.; Sancho, L. D.; Remus, R.; Aguado-Monsonet, M. Best Available Techniques (BAT) Reference Document for Iron and Steel Production; Industrial Emissions Directive 2010/75/EU: Integrated Pollution Prevention and Control; Institute for Prospective and Technological Studies, Joint Research Centre: Seville, Spain, 2013.

(49) Fisher, R.; Garcia Carcedo, E.; Alaiz Alvarez, E.; Pietruck, R. Influence of sinter mix materials on the environmental impact of high productivity iron ore sintering. EUR 2005, No. 21429, 1-101.

(50) Hasanbeigi, A.; Price, L.; Lu, H.; Lan, W. Analysis of energyefficiency opportunities for the cement industry in Shandong Province, China: A case study of 16 cement plants. Energy 2010, 35 (8), 34613473.

(51) Lammel, G.; Stemmler, I. Fractionation and current time trends of PCB congeners: evolvement of distributions 1950-2010 studied using a global atmosphere-ocean general circulation model. Atmos. Chem. Phys. 2012, 12 (15), 7199-7213. 